\title{
QUILOMBOS E DEMARCADORES DE IDENTIDADES ANÁLISE SUCINTA DE TRÊS CASOS NO ESTADO DO ESPÍRITO SANTO
}

\section{QUILOMBOS AND DEMARCADORES OF IDENTITIES SUCCINCT ANALYSIS OF THREE CASES IN THE STATE OF ESPÍRITO SANTO}

Osvaldo Martins de Oliveira ${ }^{1}$

\section{RESUMO}

Este artigo é resultado de pesquisas etnográficas em desenvolvimento com comunidades quilombolas no estado do Espírito Santo que tomam o jongo e o caxambu como referência cultural para demarcarem suas identidades. Além de uma breve abordagem teórica sobre etnicidade e memória, também passo de forma sucinta em algumas referências bibliográficas sobre quilombos, territórios negros e jongos, para depois analisar três casos etnográficos no Espírito Santo. Analiso, a partir de dados de pesquisas, a relação entre comunidades quilombolas e as culturas de jongos e caxambus, e concluo que tais práticas culturais tornaram-se referenciais da identidade dessas comunidades, pois os processos e contextos sociais nos quais sempre estiveram envolvidas levaram-na a desencadearem a transmissão de saberes e tomada de consciência sobre sua própria existência e sobre seus direitos. Essa consciência do ser quilombola é múltipla e dinâmica, ocasionando diferentes modos de apropriação comunitária dos saberes e práticas culturais herdadas para demarcarem seus territórios e identidades étnicas.

Palavras-chave: Quilombos. Identidades. Jongos. Caxambus. Patrimônio Cultural.

\footnotetext{
${ }^{1}$ Professor Adjunto de Antropologia na Universidade Federal do Espírito Santo, Vicecoordenador do Comitê Quilombos da Associação Brasileira de Antropologia na Gestão 2015-2016. Doutor em Antropologia Social, Vitória (ES). Brasil. E-mail: oliveira.osvaldomartins@gmail.com.
} 


\section{ABSTRACT}

This article is the result of ongoing ethnographic researches with quilombola communities in the State of Espírito Santo who take jongo and caxambu as cultural reference to mark their identities. In addition to a brief theoretical approach to ethnicity and memory, I also visit briefly some references about quilombos, black territories and jongos, to then look at three ethnographic cases in the Espírito Santo. I Analyze, from survey data, the relationship between quilombo communities and jongos and caxambus cultures, and conclude that such cultural practices have become benchmarks of the identity of these communities, because the processes and social contexts in which they were always involved, led-on to trigger the transmission of knowledge and awareness of their own existence and on their rights. This consciousness of the quilombola beeing is multiple and dynamic, resulting in different ways of community ownership of cultural knowledge and practices inherited to demarcate their territories and ethnic identities.

Keywords: Quilombos. Identities. Jongos. Caxambus. Cultural Heritage. 


\section{Introdução}

Até meados da década de 1990, quando iniciei meus trabalhos de campo etnográficos em comunidades de quilombos no estado do Espírito Santo, a sua existência quase não era mencionada pela literatura ou pelos meios de comunicação do mesmo estado. Algumas menções eram feitas por lideranças de movimentos negros às comunidades Divino Espírito Santo, no município de São Mateus; Santana, em Conceição da Barra; e Cacimbinha e Boa Esperança, no município de Presidente Kennedy. Atualmente, 20 anos após ter iniciado, em 1996, minhas primeiras incursões etnográficas nessas comunidades; suas lideranças - motivadas pelos direitos sociais, culturais e territoriais prescritos pela Constituição Federal de 1988, bem como pelo Decreto 4.887/2003, que estabelece as normas de regularização dos territórios dos quilombos - falam em cerca de 50 dessas comunidades, das quais, até 23 de fevereiro de 2015, 34 foram reconhecidas pelo Estado brasileiro, por meio da Fundação Cultural Palmares do Ministério da Cultura, como remanescentes dos quilombos no Espírito Santo, e outras 4 estavam aguardando complementação de documentação e visita técnica.

Este artigo, além de ser resultado de pesquisas etnográficas realizadas nas décadas de 1990 e 2000, reúne também dados recentes dos programas de pesquisa e extensão "Territórios e territorialidades rurais e urbanas: processos organizativos, memórias e patrimônio cultural afro-brasileiro das comunidades jongueiras do Espírito Santo" (2012) e "Jongos e caxambus: culturas afro-brasileiras no Espírito Santo" (2013), que foram executados por uma equipe interdisciplinar da Universidade Federal do Espírito Santo sob a minha coordenação².

\footnotetext{
${ }^{2}$ A equipe desses programas foi constituída pelos seguintes docentes e discentes da UFES: Coordenação - Osvaldo Martins de Oliveira (DCSO-PGCS); supervisão Maria Aparecida Santos Barreto (Vice-Reitora - na memória); docentes - Aissa Afonso Guimarães (CAR e PPGA) e, em 2013, entrou Sandro José da Silva (DCSO); pesquisadores - Clair da Cunha Júnior (Artes) e Patrícia Gomes Rufino (Educação). Discentes bolsistas de graduação: Andhielita Ferraz (Música), Larissa Albuquerque Silva (Ciências Sociais), Luiz Henrique Rodrigues (Ciências Sociais), Rosana Henrique de Miranda (Ciências Sociais) e Jane Seviriano Siqueira (Ciências Sociais). Em dois anos, 2012 e 2013, as ações realizadas pelos programas foram quatro oficinas de mobilização e sobre organização comunitária, memórias e patrimônio cultural (cantos, danças, ritmos e instrumentos musicais) e o II Encontro Estadual de Jongos e Caxambus.
} 
O objetivo deste artigo é descrever e analisar as práticas culturais, especificamente de jongos e caxambus, enquanto bens apropriados pelas comunidades quilombolas como demarcadores de suas identidades. Para tanto, analisarei três casos, embora existam diversos outros, onde as comunidades se autodefinem e são reconhecidas como remanescentes dos quilombos e realizam eventos festivos de jongos e caxambus como demarcadores de suas identidades quilombolas.

Em meus trabalhos etnográficos anteriores, a metodologia de pesquisa sempre foi a da observação participante, mas a que norteou a pesquisa dos referidos programas junto às comunidades jongueiras e quilombolas, consistiu em visitas da equipe aos finais de semana e em feriados para participação e observação direta em reuniões e celebrações festivas, onde verificou-se as relações de interação nessas festas, quando uma comunidade convidada visita a outra, ocorrendo ali processos sociais de trocas e de transmissão de saberes relativos à organização comunitária e à própria ação poética e criativa gestada nas rodas de jongos e caxambus que se tornam os ápices desses encontros. Nessas visitas, enquanto integrantes dos programas, realizamos entrevistas gravadas em áudios e filmagens, bem como realizamos anotações em diários de campo e fotos de acontecimentos e afazeres da vida cotidiana e dos eventos festivos. Portanto, o presente artigo consiste na análise dos dados obtidos por esses programas e por etnografias que realizei em empreendimentos etnográficos anteriores junto a essas mesmas comunidades.

A elaboração do artigo está estruturada em quatro partes. A primeira, além de elaborar considerações teóricas que fundamentam a temática da identidade quilombola a partir dos conceitos de etnicidade, memória e tradição, escava a relação entre quilombolas e a prática cultural dos jongos e caxambus, analisando alguns dados historiográficos e as memórias dos integrantes dos grupos pesquisados sobre essa relação. A segunda parte se encarrega da descrição e análise do território quilombola de São Cristóvão e Serraria, detalhando os discursos das lideranças locais sobre a valorização do trabalho coletivo e a visão de que o jongo é um momento de celebração e de festa que coroa as atividades coletivas entorno do trabalho. A terceira parte é dedicada à análise dos dados etnográficos sobre o "Caxambu da Santa Cruz", enquanto um demarcador da identidade quilombola na comunidade de Monte Alegre, onde existe a concepção política de que esse caxambu é 
uma herança dos "troncos" (ancestrais) da comunidade. A última parte trata dos dados da memória de integrantes da comunidade quilombola de Cacimbinha e Boa Esperança que denominaram o seu jongo como "Mãe África, pátria amada Brasil", em uma espécie de valorização da visão de mundo de que a África é uma grande mãe dos quilombolas jongueiros, que há muito tempo reivindicam sua cidadania por meio do direito constitucional ao reconhecimento de sua identidade, patrimônio cultural e a titulação de seus territórios.

\section{Quilombos e jongos: considerações teóricas, historiográficas e etnográficas}

O processo e o contexto social que desencadeou a formação das comunidades dos quilombos no Brasil e no Espírito Santo, segundo verifiquei em suas memórias, na literatura e na documentação sobre o tema, começou muito antes do seu reconhecimento constitucional no final do século XX. Conforme escrevem Munanga (1995) e Nascimento (1980), as experiências sociais do passado que proporcionaram a formação da visão de mundo das organizações sociais denominadas quilombos, que já vinham sendo empregadas pelas lideranças de organizações de movimentos negros desde a primeira metade do século $\mathrm{XX}$, ao surgirem no Brasil dos séculos XVII a XIX, era uma herança dos povos africanos de língua banto. O termo quilombo, neste contexto, ao que escreve Munanga (1995), era empregado para se referir à organização social de vilas, povoados, capitais, feiras, mercados e acampamentos guerreiros.

$\mathrm{Na}$ perspectiva antropológica, ainda que se reconheça um conteúdo histórico, os quilombos no Brasil têm sido definidos como tipos organizacionais do presente, onde seus integrantes recorrem à diferentes experiências e saberes herdados de seus antepassados, acrescentando contribuições novas por meio de um processo social de ressemantização e têm a preocupação em transmitir suas inovações às gerações futuras. Isso é possível porque o quilombo, conforme escreve Almeida (2000; 2002), tem se constituído em um processo de interação social baseado na autonomia na produção e nas trocas comerciais, embora, segundo meus dados etnográficos, diversos agentes de instituições estatais e das 
iniciativas de interesse privado da exploração da mão-de-obra tenham, historicamente, tentado impedir que essa autonomia se consolide.

Após a Constituição Federal de 1988, observando os processos de mobilização das organizações de movimentos negros e quilombolas e de trabalhadores rurais, os antropólogos integrantes do Grupo de Trabalho "Terra de Quilombo", da Associação Brasileira de Antropologia (ABA), que há alguns anos vinham estudando esses movimentos e mobilizações das comunidades negras do meio rural pelo direito ao território e ao pertencimento ao lugar e grupos específicos, em 1994, em diálogo com a teoria de Barth (1969), apresentaram a seguinte definição para quilombo:

O termo 'quilombo' tem assumido novos significados na literatura especializada e também para os grupos, indivíduos e organizações. Ainda que tenha um conteúdo histórico, o mesmo vem sendo ressemantizado para designar a situação presente dos segmentos negros em diferentes regiões e contextos do Brasil. Definições têm sido elaboradas por organizações não-governamentais, entidades confessionais e organizações autônomas de trabalhadores, bem como pelo próprio movimento negro. ...o termo 'remanescente de quilombo' vem sendo utilizado pelos grupos para designar um legado, uma herança cultural e material que lhes confere uma referência presencial no sentimento de ser e pertencer a um lugar e a um grupo específico (ABA, 1994).

Deste modo, o presente artigo, elaborado a partir das etnografias mencionadas acima e em diálogo com o GT Terra de Quilombos da ABA, que atualmente é denominado Comitê Quilombos, do qual faço parte, se fundamenta nos pressupostos teóricos dos estudos sobre etnicidade e memórias, que entendem que as referências e práticas culturais e memórias são produtos e resultados de formas de organização social específicas, pois em uma sociedade pluriétnica como a brasileira não é possível conceber essas práticas e referências como algo homogêneo. Ao contrário, entorno delas existem disputas e, por parte das classes e grupos maioritários, foram realizadas campanhas de desqualificação das práticas culturais e memórias das minorias étnicas afro-brasileiras, como se observa nos estigmas atribuídos aos antigos e atuais atores sociais protagonistas de formas de organização social como os quilombos e de produções culturais como os jongos, caxambus, sambas, capoeiras, congo e congadas. Assim, ao analisar os jongos e 
caxambus como referências e demarcadores culturais da identidade quilombola no estado do Espírito Santo, adoto as perspectivas sociológicas e antropológicas de Weber (1920), Barth (1969, 1984, 1994, 2000) e Pollak (1989, 1992), segundo as quais, coletividades de homens e mulheres que compartilham sentimentos de pertencimento a uma mesma terra (ou continente) de origem, assim como compartilham práticas culturais e lembranças que, se estão conscientes dessa procedência étnica, estão condenados a serem sujeitos na construção de uma história e destinos (ou projetos) compartilhados.

Deste modo, ao adotar as perspectivas mencionadas acima sobre etnicidade, cultura e memória, passei a defender que memórias e identidades quilombolas possuem ingredientes fundamentais, tais como pessoas/personagens (na maioria das vezes coletivas, como lideranças e mestres de saberes tradicionais), lugares (paisagens, monumentos, imagens, fotos, filmes, arquivos, bibliotecas, músicas), datas, eventos e acontecimentos (festas, festivais, romarias, procissões, desfiles) e invenções. Entendo também que as comunidades dos quilombos constituem-se em localidades que podem ser definidas como territórios negros (rurais e urbanos), nos termos de Leite (1991), pois estão demarcados por referências culturais de matrizes africanas e afrobrasileiras. Tais referências, nos casos em análise, além do jongo e caxambu, são também os denominados "ajuntamentos" para os trabalhos coletivos nas lavouras, as rezas de ladainhas para divindades dos altares católicos, as práticas religiosas relacionadas às religiões de matrizes africanas como os terreiros de umbanda na comunidade quilombola de Monte Alegre e as denominadas "mesas de santo"3 nas

\footnotetext{
${ }^{3} \mathrm{O}$ termo "mesas de santo" surge pela primeira vez na literatura sobre as comunidades negras do norte do Espírito Santo na Carta Pastoral do bispo Dom João Batista Correa Nery (1963). Segundo o que escreve o bispo, essas mesas eram parte de um culto afrobrasileiro de origem banto, denominado cabula. Segundo o mesmo bispo, o culto era composto por três mesas de santo: mesa de Santa Maria, mesa de Santa Bárbara e mesa de Cosme e Damião. Essas duas últimas mesas, conforme constatei em pesquisa etnográfica, continuam existindo nas comunidades quilombolas do Sapê do Norte, mas a nomeação dos rituais, como cabula e mesa de Santa Maria, que eram os rituais mais secretos, feitos no meio da mata e só poderia participar quem fosse convidado, ao que relatam os quilombolas, não existe mais. A cabula, segundo a memória dos antigos quilombolas e jongueiros, existiu com esse nome até a década de 1980, sendo seus líderes perseguidos e assassinados por agentes da polícia e de grupos de extermínio. $\mathrm{Na}$ visão dos descendentes dos antigos cabuleiros, o bispo teria sido enganado (encabulado) pelos relatos dos antigos integrantes da cabula, que tinham o dever religioso de ocultar onde estavam as mesas de Santa Maria, apontando que as outras duas mesas faziam parte do culto, mas para eles, apenas a mesa de Santa Maria era parte da antiga cabula.
} 
comunidades quilombolas do Sapê do Norte. Soma-se a essas referências e demarcadores, o baile dos congos de São Benedito, mais conhecido como ticumbi, na mesma região do Sapê do Norte, organizado por integrantes dessas comunidades.

Conforme se verifica nos estudos sobre jongos e caxambus da Região Sudeste do Brasil, essas referências culturais - assim como o termo e a experiência de quilombo - têm procedência nas tradições dos povos bantos e foram organizadas inicialmente pelos negros escravizados nas fazendas produtoras de café dessa região do país. Conforme descrevo e analiso em diferentes casos no Espírito Santo, esses são demarcadores culturais da identidade quilombola selecionados pelos integrantes de tais comunidades.

Tendo em vista que os quilombolas referem-se aos demarcadores de suas identidades como tradições, para explicar tal conceito recorro a Barth (1984) que emprega a expressão "tradições culturais", no sentido de alguma coisa que as pessoas "herdam, empregam, transformam, acrescentam e transmitem”. Essas tradições pressupõem a existência de organizações sociais onde são praticadas e transmitidas. O conhecimento, os costumes e os valores distintivos da tradição são adaptados e afirmados na ação, sendo apropriados por atores sociais como elementos de valorização da identidade coletiva. Por isso, na identificação dos componentes da tradição, o foco da análise deve ser as organizações sociais distintivas e as identidades coletivas, demonstrando a interconexão entre organização social existente e a forma e conteúdo da tradição, de tal modo que as duas coisas estão refletidas uma na outra (BARTH, 1984, p. 80 - 82).

Conforme verifiquei na etnografia, as lideranças de comunidades quilombolas e das organizações sociais para práticas culturais dos jongos e caxambus legitimam a antiguidade de suas tradições, recorrendo à memória de seus ancestrais para afirmarem que o jongo e o caxambu têm cerca de 200 anos. Não é minha intenção colocar essas afirmações à prova historiográfica, mas considerei importante relacionar algumas das práticas, crenças, festas, celebrações, valores e modos de fazer, que eles chamam de suas tradições e seus "acervos culturais", com o que as referências historiográficas e documentais, que tive acesso sobre a existência de quilombos no Espírito Santo do século XIX e que também dizem respeito às suas crenças, festas e costumes. 
Entre os quilombos apontados e descritos pelas fontes documentais do referido século, segundo os trabalhos de Oliveira (2011a, 2005, 2002), Moreira (2010), Marinato (2006) e Maciel (1994), além daqueles do norte e do sul do Espírito Santo, estavam também aqueles localizados nos atuais municípios de Serra, Vitória, Cariacica, Santa Leopoldina e Viana. No entanto, para este artigo, explorarei, a partir dessas fontes e autores, os dados referentes aos quilombolas e suas relações com eventos e festas de jongos e caxambus nas regiões sul e norte do mencionado estado. Para empregar uma categoria dos próprios quilombolas, daqui para frente, quando me referir aos quilombolas e aos seus territórios da região norte do Espírito Santo, que neste caso se refere aqueles que estão nos municípios de São Mateus e Conceição da Barra, empregarei territórios quilombolas (ou apenas quilombolas) do Sapê do Norte.

O termo Sapê do Norte, enquanto denominação dos quilombolas da região que inclui a maior parte dos territórios das comunidades estudadas, conforme escrevi em outro momento (OLIVEIRA, 2011b, p. 6), se refere a uma gramínea bastante abundante nas terras cultivadas pelas famílias negras e que não é consumida pelo gado e nem pelos animais de carga.

Nos discursos de mobilização política em favor dos seus territórios, as lideranças quilombolas afirmam que o sapê não é apenas aquilo que se deixa ver, pois o segredo de sua força e resistência ao extermínio está além das aparências e das superfícies da terra. Deste modo, o sapê pode ser tomado como metáfora para a análise dos embates políticos das comunidades quilombolas por seus territórios, pois a luta é por um bem que supera a perspectiva mercadológica da terra como mercadoria, tratando-se do território enquanto um conjunto de saberes e fazeres que envolve não apenas as práticas produtivas, mas também os ritos, os saberes e os processos organizativos acerca das práticas e da vida. O termo Sapê do Norte, comumente empregado nas narrativas dos quilombolas do norte do Espírito Santo para se referirem a grande extensão territorial onde viviam seus antepassados e onde se encontra a maior parte das comunidades ainda hoje, é concebido também como territorialidade, no sentido de englobar suas práticas, modos de vida e saberes. (OLIVEIRA, 2011b, p. 06).

Os dados mais antigos a que tive acesso sobre a possível relação entre quilombolas e a prática do jongo nas regiões norte e sul do Espírito 
Santo vêm das descrições do viajante austríaco, o príncipe Von Maximiliano Wied-Neuwied, que passou pela província entre 1814 e 1817. Na vila de Guarapari, no litoral ao sul da capital da província, ele descreveu o que chamou de "República Negra", que se referia a um agrupamento negro independente que existia nas proximidades da vila, que era formado pelos ex-escravizados das fazendas do Campo e Engenho Velho, que após a morte do proprietário se revoltaram, passaram a trabalhar menos, considerando-se livres e recusando a se submeterem a uma nova administração. A República Negra contava com cerca de 600 integrantes. Ao norte, ao se aproximar da Fazenda Itaúnas, que pertencia ao ouvidor da comarca de Porto Seguro, o mesmo viajante afirmou ter ouvido toques de tambores e cantigas dos escravizados, o que lhe fez concluir que se tratava de uma tentativa de manutenção de costumes advindos de suas terras de origem. Ele observou que entre os negros, apesar do papel predominante do tambor, encontravam-se todos os instrumentos de música referidos pelos viajantes da África. Baseando-me nos dados de Maximiliano, os indícios apontam que o jongo entre os quilombolas do Sapê do Norte, assim como as expressões religiosas e culturais dos afro-brasileiros associadas aos tambores, podem ter surgido no início do século XIX. Como observei em outro texto (OLIVEIRA, 2011a), o registro escrito feito pelo referido viajante, ao que indica a falta de fontes, é um dos primeiros sobre o uso do tambor, que veio a se tornar o instrumento musical e símbolo central nos cultos religiosos das mesas de santo e dos jongos e caxambus nas comunidades quilombolas do Espírito Santo. O toque dos tambores, à noite no meio da mata, em 1848, como observo adiante, serviu como indício para que os moradores do vale do Rio Muqui, no sul da Província, levassem ao delegado de polícia do distrito de Itapemirim a denúncia de que nas matas próximas ao mesmo rio se encontrava um quilombo.

Detalhando um pouco mais os dados de cada região, observo que na região norte da província, na então vila de São Mateus, entre os anos de 1827, 1835 e 1839 existiam quilombos nos sertões e nos subúrbios da vila com cerca de 90 e 100 integrantes. Frente a isso, os demais moradores e a Câmara de São Mateus enviaram documentos ao Governo da Província solicitando providências. Ao que apontam os indícios, a preocupação dos senhores e do delegado de polícia da vila se devia ao fato de os quilombolas, conforme se verifica nos relatórios de polícia e do presidente da Província dos referidos anos, estarem estabelecendo 
relações comerciais com a vida social urbana e com comerciantes do entorno. No final da primeira metade do século XIX, especificamente em 1849, voltam as informações de que no meio rural de São Mateus haviam quilombos. No entanto, é na segunda metade do mesmo século, especificamente 1866, 1881 e 1884, que voltamos a encontrar dados sobre a localização de quilombos e o número de seus integrantes, acrescentando os nomes de seus líderes. Esses lugares, segundo os dados de 1866, são de números indefinidos e suas denominações são genéricas, como os "sertões de São Mateus". Os números de integrantes para cada quilombo, segundo a estimativa da polícia, variava de 16 a 20. Em 1881, um quilombo localizado na vila de Santana, no atual município de Conceição da Barra, contava com cerca de 20 integrantes e era liderado por Rogério. Os integrantes desse quilombo trocaram tiros com a força policial do presidente da Província, seu líder foi assassinado e os demais quilombolas, pelos indícios deixados pelo relatório do mesmo presidente, escaparam pelas matas da região, visto que nem bem a força policial tomou o vapor de volta à capital, esses quilombolas, segundo o mesmo relatório, teriam reaparecido na vila da Barra do São Mateus (atual Conceição da Barra), praticando latrocínios em busca de alimentos. Três anos depois, em 1884, um quilombo se encontrava organizado nas matas do Campo Redondo, na região de São Mateus, sob a liderança de Benedito (que ficou conhecido entre os quilombolas do Sapê do Norte como Benedito Meia-Légua), que o relatório de polícia o definia como "réu de morte", "facínora" e era temido pelos senhores e pela polícia. A população desse quilombo, segundo a estimativa dos documentos de polícia, variava de 20 a 30 integrantes.

Segundo Oliveira (2011a), o relato de polícia de 1884, inscrito no relatório do presidente da Província do mesmo ano, ${ }^{4}$ descreve que na Vila de Santana da época, havia dois grupos negros organizadores da Festa de Nossa Senhora de Sant'Anna: um grupo se nomeava como Primoso e o outro Sornamby. Esses grupos, segundo o relato de polícia, mantinham segredo absoluto sobre quem eles convidavam para a festa, levantando a suspeita e os temores das autoridades senhoriais de que o quilombo liderado por Benedito apareceria na festa para proclamar o grito de liberdade. A respeito da predominância de negros nesta festa e

\footnotetext{
${ }^{4}$ Relatório com que José Camilo Ferreira Rebello, quinto vice-presidente da província do Espírito Santo, passou a administração ao presidente Custódio José Ferreira Martins, em 17 de setembro de 1884.
} 
do impedimento por parte deles de as autoridades obterem informações seguras sobre os festejos em homenagem a Sant'Anna, escreve o historiador Robson Martins:

Há indícios de que, no fim do século XIX, os escravos de São Matheus formavam uma comunidade envolvendo tanto os escravos da lavoura quanto os da própria cidade, e que, em dias de festas para santos, encontravam-se para comemorar, matar as saudades, rever os amigos e parentes, etc. (MARTINS, 2000, p.2).

Como aponta a fonte historiográfica acima, os atuais eventos festivos negros quilombolas na região norte têm mais de um século de história e tinha por objetivo reforçar as relações entre os escravizados e, ao que indica o relatório de polícia acima mencionado, desses com os quilombolas que viviam arranchados nos quilombos. A respeito da festa enquanto lugar e organização coletiva de construção de identidade no Sapê do Norte, acrescenta Ferreira:

A festa de devoção a Nossa Senhora de Sant'Anna passara a constituir, de fato, um espaço identitário dos negros, organizado e participado somente por eles, que ali construíam a oportunidade do encontro entre seus iguais. A exclusividade negra deste espaço fortalecia o sentimento de identidade dos escravos frente à sociedade branca e escravista. Ademais, sob a bênção da santa padroeira, o grupo tornava-se protegido e fortalecido, sentimento que favoreceu o planejamento de revoltas escravas no transcorrer de todo o escravismo colonial brasileiro. Neste sentido, ao constituírem-se enquanto espaços identitários dos negros, as festas de devoção provocavam o temor das autoridades que tinham como missão garantir a permanência da ordem colonial escravista (FERREIRA, 2009, p. 244).

Na região sul da então província, os dados historiográficos sobre a existência de quilombos vêm de dois marcos temporais: 1830 e 1848 . Do primeiro marco vem os dados de uma caçada aos quilombos no então distrito de Itapemirim, quando o delegado de polícia distrital convocou soldados e índios Puri para destruírem um quilombo, sendo que quatro integrantes do mesmo teriam escapado pelas matas da região. No ano 1848, a polícia informa a existência de quilombos no meio rural do mesmo distrito e que um deles estava localizado no Sertão da Pedra Lisa, onde, conforme veremos adiante pela memória da comunidade quilombola de Monte Alegre, era também lugar de encontro de 
caxambuzeiros. Um dado de grande relevância para a relação quilombos e jongos-caxambus, também vem de 1848 na mesma região, quando, segundo Moreira (2010), um quilombo nas matas próximo ao Rio Muqui foi descoberto pelo delegado de polícia de Itapemirim, que contou com a ajuda de moradores que teriam ouvido "toques de tambores", "cantos de galos" e "fumaça na mata", verificando que o mesmo existia há muitos anos, pois seus habitantes foram estimados variando de 200 a 300 integrantes, advindos de fazendas do norte fluminense e do sul do Espírito Santo.

São a esses e outros quilombos do passado no Espírito Santo que as lideranças quilombolas do presente recorrem para falar de suas formas de organização e tradições herdadas. Cabe observar que essas estratégias de valorização de personagens e organizações negras do passado não são novas entre os movimentos sociais negros, pois a Frente Negra Brasileira na década de 1930, o Teatro Experimental do Negro em 1945, o Movimento Negro Unificado a partir do final da década de 1970 e os Agentes de Pastoral Negros (APN's) a partir da década de 1980 recorriam à memória e à escrita para argumentarem que os segmentos étnicos negros tinham (e têm) particularidades políticas históricas e tradições culturais nas formas de organização advindas dos quilombos desde o século XVII. Algumas dessas organizações e suas lideranças no estado do Espírito Santo empregam o termo quilombo e os nomes de personagens negras e quilombolas do passado para nomearem suas organizações no presente, como é possível listar alguns casos: a) Quilombo Regional do Espírito Santo, para o caso dos APN's; b) Nação Zumbi Ojab, em Vila Velha, para homenagear o líder do Quilombo de Palmares; c) Associação Cultural Ganga Zumba, em Vitória, para homenagear o outro líder do Quilombo de Palmares; d) Núcleo de Mobilização e Reflexão Elisiário, que nos anos 1980 estava ligado ao Movimento Negro Unificado Contra o Racismo, no Morro do Quadro, na cidade de Vitória (ES), para homenagear um dos líderes da Revolta de Queimado, ocorrida no Espírito Santo em 1849; e) Coordenação Estadual Quilombola Zacimba Gaba, para homenagear a princesa e uma das primeiras lideranças quilombola no Espírito Santo do século XIX; f) Fundação Cultural Benedito Meia-Légua, localizada em Conceição da Barra, para manter viva a memória de um dos mais temidos líderes quilombolas do território do Sapê do Norte (ES); g) bairro Quilombo, localizado no distrito de Santana, Conceição da Barra, renomeado por pressão do Grupo de União e Consciência Negra (GRUCON), que atuou 
no município na década de 1980, e neste bairro, foi criado com recursos do Ministério de Desenvolvimento Social (no Governo de Luiz Inácio Lula da Silva), por demanda do movimento quilombola, o CRAS Quilombola "Negro Rugério" para manter viva a memória de Rogério, líder do quilombo que existiu na vila de Santana e foi assassinado em 1881, conforme mencionei anteriormente.

No que diz respeito à relação quilombos e jongos, verifica-se que no bairro Quilombo e no bairro vizinho de Santana Velha, existem dois grupos de jongos: um para São Bartolomeu e outro para Nossa Senhora de Sant'Ana. Cinco quilômetros ao norte, está a comunidade quilombola de Linharinho, onde se encontra o jongo de Santa Bárbara e, quatro quilômetros ao sul do mesmo bairro, está a comunidade quilombola de Porto Grande, com o seu jongo de São Cosme e Damião. Nestas comunidades do grande território quilombola do Sapê do Norte, encontra-se uma realidade etnográfica efetiva da relação entre quilombos e prática cultural do jongo.

O jongo é uma das várias referências culturais que as lideranças das organizações sociais afro-brasileiras tomam como sinais diacríticos para a diferenciação e a construção da fronteira étnica. Em 2005 ele foi reconhecido pelo Instituto do Patrimônio Histórico e Artístico Nacional (Iphan) como patrimônio cultural brasileiro. A partir dos dados publicados pelo Iphan no Dossiê do Jongo (2005) é possível afirmar que o jongo é uma referência cultural criada no Brasil pelas capacidades poéticas e artísticas de africanos de origem banto e seus descendentes, que foram escravizados nas fazendas de café na região Sudeste brasileira.

No Espírito Santo, segundo os dados dos programas de extensão já citados, o nome jongo se refere às cantigas ou pontos entoados nas denominadas "rodas de jongos" ou "rodas de caxambu". Caxambu, no sul do estado, é o nome atribuído ao tambor, o principal símbolo e instrumento tocado nessas rodas e celebrações ritualísticas. No norte, os jongueiros se definem coletivamente como grupos de jongo, referindose ao conjunto do ritual. As rodas de caxambu ou jongo são realizadas por comunidades jongueiras que se reúnem para tocar instrumentos musicais (tambor, ganzá ou reco-reco), dançar e cantar de forma poética e desafiadora às diversas situações sociais vividas pelas comunidades. Desse modo, em alguns momentos empregarei o termo "jongo- 
caxambu" para me referir a esse círculo ritualístico, dinâmico e mutável nas referidas comunidades.

Além de realizar pesquisa de campo e ações de extensão, os programas referidos acima tiveram também como ponto de partida a análise de direitos e políticas públicas de salvaguarda do patrimônio cultural criadas a partir dos artigos 215 e 216 da Constituição Federal do Brasil de 1988. Esses direitos culturais estabelecem o dever do Estado em apoiar e incentivar a valorização das manifestações culturais populares, indígenas e afro-brasileiras que participam do processo civilizatório nacional. Nesse sentido, a partir de uma política de salvaguarda coordenada pelo Iphan, o jongo foi reconhecido como patrimônio cultural brasileiro. Esse reconhecimento foi precedido por um conjunto de mobilização política dessas comunidades jongueiras, como os encontros de jongueiros que vinham ocorrendo no Rio de Janeiro e em São Paulo desde 1996 para discutir a especificidade dessa tradição cultural e a realização, pelo Iphan, entre os anos de 2001 e 2005, do Inventário de Referências Culturais do Jongo do Sudeste do Brasil, sob a coordenação geral da antropóloga Letícia Viana. Nesse inventário, embora se mencione a existência de grupos de jongo no Espírito Santo nos municípios de Presidente Kennedy, São Mateus e Conceição da Barra, apenas o grupo de jongo de São Benedito, da cidade de São Mateus, passou a participar, no ano de 2006, da articulação dos grupos que se inseriram no Pontão de Cultura do Jongo do Sudeste, que tem sede na cidade de Niterói, no Rio de Janeiro. Depois dos primeiros encontros das comunidades jongueiras do Sudeste, segundo a professora Elaine Monteiro, coordenadora do Pontão do Jongo do Sudeste, passaram a chegar reivindicações de que no Espírito Santo existiam grupos de jongo não apenas em São Mateus.

Diante de tais demandas, a Superintendência do Iphan no mesmo estado reuniu informações acerca da existência de 12 grupos jongueiros e, a partir de então, deram-se início às mobilizações para o primeiro Encontro de Grupos de Jongos e Caxambus no Espírito Santo, que ocorreu nos dias 3 e 4 de outubro de 2009, na comunidade de Vargem Alegre, Cachoeiro de Itapemirim (ES), onde se organiza o grupo do Caxambu Alegria de Viver. Nesse encontro, apareceram 16 grupos, que passaram a se mobilizar para que surgisse o segundo Encontro Estadual de Jongos e Caxambus, que foi realizado nos dias 20 e 21 de outubro de 
2012, como uma das ações dos programas de extensão da UFES, citados anteriormente.

Segundo os dados dos mesmos programas de pesquisa e extensão, o maior número de agrupamentos de jongos e caxambus pesquisados até o momento se encontra no estado do Espírito Santo, com 24 grupos, sendo 14 na região sul e 10 na norte. Os agrupamentos visitados e pesquisados na região sul foram: Tambores de São Mateus, da comunidade quilombola de São Mateus, município de Anchieta; Grupo de Jongo de São Benedito Sol e Lua, cidade de Anchieta; Jongo Mestre Wilson Bento e Jongo Mirim Cryspiniano Balbino Nazareth, ambos na cidade de Itapemirim; Jongo "Mãe África, pátria amada Brasil", da comunidade quilombola Boa Esperança e Cacimbinha, município de Presidente Kennedy; Caxambu da Vovó Rita, Morro Zumbi, cidade de Cachoeiro de Itapemirim; Caxambu Alegria de Viver, comunidade negra de Vargem Alegre, Cachoeiro de Itapemirim; Caxambu da Santa Cruz, da comunidade quilombola de Monte Alegre, Cachoeiro de Itapemirim; Caxambu de Andorinhas, da comunidade de Andorinhas, em Jerônimo Monteiro; Caxambu do Horizonte, distrito de Celina, município de Alegre; Caxambu da Família Rosa, bairro São Pedro, cidade de Muqui; Caxambu do bairro Santo Antônio de Muqui, município de Mimoso do Sul; Caxambu (na memória) da comunidade quilombola de Pedra Branca, meio rural do município de Vargem Alta; Caxambu (na memória) do Córrego do Amarelo, município Divino São Lourenço. Na região norte, os programas pesquisaram e reuniram dados sobre seis grupos no município de Conceição da Barra (Jongo de São Benedito e São Sebastião, de Itaúnas; Jongo de Santa Bárbara, da comunidade quilombola de Linharinho; Jongo de São Bartolomeu, no bairro Quilombo; Jongo Nossa Senhora de Sant'Ana, no bairro Santana Velha; Jongo de São Cosme e Damião, na comunidade quilombola de Porto Grande; Jongo São Benedito das Piabas, da comunidade de Barreiras), três no município de São Mateus (Jongo de Santo Antônio, da comunidade quilombola de São Cristóvão e Serraria; Jongo de São Benedito, no bairro Sernamby; e Jongo de São Benedito, da comunidade de Campo Grande) e um no município de Linhares, o Tambor de São Benedito, da comunidade do Guaxe.

Antes de passar dessa lista de agrupamentos pesquisados para a descrição e análise de três casos, cabe aqui uma breve interpretação do significado do símbolo maior dos grupos de jongos e caxambus, que é o 
tambor. Em alguns grupos o tambor é denominado de caxambu, e, ao mesmo tempo, por receber esse nome, ele nomeia os grupos e, só para citar um exemplo entre tantos, descreverei adiante o caso do "Caxambu da Santa Cruz". A respeito da fabricação do tambor, conforme narrou um dos mestres de caxambu, o jongueiro, ao passar pelas matas à procura da madeira para a fabricação do tambor, deve ficar atento à ação de um pássaro denominado pica-pau sobre a madeira de uma árvore seca ou verde, que é uma potencial matéria-prima para fabricação artesanal do tambor. A ação do pica-pau é o sintoma de que a madeira está sendo "ocada" pela atividade de insetos que se alimentam do miolo da mesma. O trabalho do pássaro, que vai abrindo espaço no miolo da árvore para se alimentar é uma colaboração ao trabalho do fabricante do caxambu. Depois de retirada e preparada essa madeira, em seu trabalho de fabricação do instrumento, o artesão associa à uma das extremidades da madeira oca o couro de gado com tarugos de madeira ou pregos, ficando o mesmo pronto para ser afinado ao calor do fogo.

Deste modo, em alguns grupos, antes de realizar uma roda de jongo ou de caxambu, os integrantes acendem uma fogueira para aquecer e afinar o couro do tambor, a ser tocado pelos tamborzeiros que têm um saber próprio para tanto e, assim exercer o seu poder de elo comunicativo entre os vivos e destes com os seus ancestrais que um dia tocaram esses tambores. O tambor é também um disparador de memória, visto que alguns jongueiros afirmam que só lembram de pontos cantados por seus antepassados quando os tamborzeiros iniciam as rodas com o rufar dos tambores. Assim, o tambor é acionador do movimento circular antihorário da roda em direção ao passado, isto é, para o encontro com os saberes herdados dos ancestrais. Vejamos os exemplos nos três casos a seguir.

\section{O território quilombola de São Cristóvão e Serraria: trabalho coletivo e jongo}

O jongo é uma brincadeira que lembra que, na época da escravidão, os escravos não podia participar dos festejos, dos banquetes dos grandões, né? [...] Que aqui tinha coronéis e capitão. Bom, então não podia participar dessa festa. Então, fazia a festa deles. Tocava o tambor deles. Ia lá no mato, tocava o tambor deles. Então, não era macumba, era totalmente uma diversão, né? Louvando a 
Deus pelo trabalho coletivo que eles fazia junto. Lá tava trabalhando, agora nós vamos festejar. Fazia comida, muita comida, muita bebida ali e tudo mais. Aí, ia festejar. [...] Eles tinha aquele jongo como um festejar o trabalho que fazia. Aquilo toda vida, essa comunidade aqui trabalhava em coletividade. Hoje que é estranho falar em coletividade. Quando fala de coletividade hoje dentro de uma assembleia, deputado repudia, governo de estado repudia a gente, né? A gente tem batido de frente. [...] Que a gente é repudiado. Então, toda vida dentro desse território, os quilombolas só trabalhava em coletividade, trabalho de mutirão. Uma pessoa num pode pagar a outro, então a gente vai lá junto. Fala mutirão, outro fala assim, juntamento [...]. Mais assim, sempre trabalhando no coletivo pra pessoa num tá pagando do bolso. E desde a... Por quê? Aí nós tem aquela raiz, é dando continuidade àquele passado, porque era assim que eles fazia. Então, diante desse trabalho pesado que fazia, eles rezava. Tinha primeiro no pé do cruzeiro. Não tinha igreja, eles rezava é no pé do cruzeiro, pedindo, mais certamente, vinha a chuva. Aquilo resolveram em coletividade, eles fizeram uma igrejinha. Fizeram essa igrejinha e deram continuidade. Após a reza, aí tinha, né? Tinha ladainha nas casas, era devoto de Santo Antônio, devoto de São Pedro, devoto de Santana, devoto de São João. Cada quais, cada família tinha devoção com um santo. Aí naquela data do dia daquele santo aí era uma ladainha, além da reza da igreja, tinha que rezar uma ladainha. (NASCIMENTO, S., 2012).

O território quilombola de São Cristóvão e Serraria está localizado no município de São Mateus (ES), em uma região denominada Sapê do Norte, onde se encontram cerca de 30 comunidades quilombolas. Está situado à margem direita da corrente do rio Cricaré e dista 38 quilômetros da sede do município.

Pelos tradicionais laços de parentesco, São Cristóvão e Serraria constituem um único quilombo. Ao se inserirem nos processos de mobilização das demais comunidades quilombolas do Brasil pelo direito à identidade e ao território, as 45 famílias ali existentes tiveram o seu território reconhecido como um quilombo por meio do Decreto Presidencial $\mathrm{s} / \mathrm{n}^{\mathrm{o}}$ publicado no Diário Oficial da União no dia 16 dezembro de $2010^{5}$. Essas famílias residem em pequenas áreas de terras,

\footnotetext{
${ }^{5}$ O referido Decreto Presidencial $\mathrm{s} / \mathrm{n}^{\mathrm{o}}$, de dezembro de 2010, compõe o Processo $\mathrm{n}^{\circ}$ 54340.000582/2005-15, aberto no Instituto Nacional de Colonização e Reforma Agrária desde o ano de 2005.
} 
e devido à morosidade do Instituo Nacional de Colonização e Reforma Agrária (Incra), o território ainda não foi titulado.

Em suas pequenas parcelas de terra, as famílias se dedicam ao cultivo agrícola de lavouras de café, pimenta-do-reino e mandioca. Da mandioca produzem farinha, polvilho, beiju, biscoitos e bolos para consumo próprio. A maior parte desses três tipos de produtos se destina a comercialização direta (para o caso dos derivados da mandioca) e indireta (por meio dos denominado atravessadores) nos mercados regionais, nacional e internacional, visto que o café e a pimenta-do-reino são exportados também para os mercados norte-americanos, europeus e chineses.

Os quilombolas do Jongo de Santo Antônio entendem que o jongo é uma invenção cultural dos seus antepassados, sendo empregada para demarcar a identidade da comunidade. Quanto à memória do jongo e dos antigos jongueiros na localidade, seus participantes remetem a sua existência há mais de cem anos, lembrando de Antônio Lucindo, considerado um dos primeiros líderes da brincadeira e que era tio avô de Antônio Nascimento, o atual mestre do grupo. Antônio acredita ter herdado não apenas o nome de seu tio, mas também a devoção a Santo Antônio, bem como a responsabilidade de zelar por essa cultura e transmiti-la às novas gerações. Afirmam que o jongo surgiu vinculado às promessas e devoções religiosas de seus antepassados a Santo Antônio, para o qual faziam festas e distribuíam alimentos. Para cumprir suas promessas, Antônio Lucindo, que é considerado o protagonista nesta devoção, matava garrotes e porcos para realizar a festa. Ele teria feito a promessa para o santo para alcançar a cura de uma doença, e por ter sido atendido, a retribuição ocorria realizando sacrifícios de animais para a festa, começando com uma reza de ladainha, seguida de roda de jongo e distribuição de alimentos e bebidas a todos os que comparecessem ao evento no dia de Santo Antônio, não importando que dia da semana fosse. Assim Lucindo teria feito até morrer, mas a tradição do jongo associada a trabalhos coletivos nas lavouras e rezas coletivas de ladainhas teria começado muito antes dele.

Os trabalhos coletivos, também conhecidos como ajuntamentos e mutirão, estão relacionados a uma espiritualidade comunitária tradicional denominada reza de ladainha que, por sua vez, precedia ao jongo. Trata-se de uma concepção organizativa que fundia essas práticas 
coletivas, pois o jongo e a reza da ladainha são expressão da organização coletiva que norteia o trabalho no quilombo de São Cristóvão e Serraria.

No núcleo do quilombo chamado Serraria, existiu no passado uma prática religiosa de origem africana banto, denominada mesa de Santa Bárbara, que era liderada por uma das ancestrais dos jongueiros locais. Havia também um jongo para a mesma santa. No entanto, devido à pressão exercida pela Igreja Católica que se expandiu na região, fez com que a referida Mesa e o jongo de Santa Bárbara fossem silenciados. A partir de então, deu-se continuidade ao jongo de Santo Antônio; enquanto as práticas culturais ligadas a Santa Bárbara ficaram reservadas às incorporações de divindades de matriz africana em ambientes familiares. O Jongo de Santa Bárbara foi interrompido com a morte de sua líder; enquanto que no Jongo de Santo Antônio, com a morte de Antônio Lucindo, a liderança ficou com Vicentina, que se tornou a sucessora da referida brincadeira. Em seguida, a sucessão ficou com o pai de Antônio e Sebastião, Mateus Nascimento, que segundo os entrevistados, "enfraqueceu" por ter ficado doente e vindo a falecer antes de preparar o sucessor. Por isso, o jongo teria ficado vários anos parado. Posteriormente, Antônio Nascimento retornou de São Paulo, onde trabalhou por vários anos, e juntamente com seu irmão Sebastião, resolveram "alavancar o jongo".

O mestre Antônio afirma que assumiu a responsabilidade de zelar pelo jongo porque, para seu povo, "o jongo sempre foi religião e diversão". Segundo ele, na época de Antônio Lucindo, "a roda de jongo" era liderada também pelas "cabeceiras" Vicentina e Maria Lucindo, irmãs do antigo mestre. As cabeceiras são mulheres, geralmente mais velhas, que ficam nas extremidades do semicírculo formado por diversas mulheres dançantes. As cabeceiras comandam os movimentos das danças que os demais integrantes devem seguir. A roda dançante do jongo só se inicia quando os tambores são tocados, o mestre puxa "o ponto de abertura" e as cabeceiras começam a dançar. Assim, o Jongo de Santo Antônio se caracteriza por uma formação circular aberta.

Quanto aos integrantes e instrumentos do grupo, atualmente existem dezesseis dançantes, três tocadores de tambores e dois tocadores de reco-reco. Os tambores são nomeados de acordo com o som que produzem, a saber: "papudo", "rojão" e "vorossa-vorossa". Este último é repicado mais fortemente quando se canta, já no final de uma roda, a 
cantiga denominada "Oi, vorossa-vorossa", exigindo maior rapidez nos movimentos da dança.

As principais funções na roda de jongo de Santo Antônio são ocupadas por pessoas que têm graus de parentesco entre si e que são lideranças em outras equipes da comunidade. Antônio Nascimento é também mestre do Reis-de-Boi e técnico da equipe de futebol; e seu irmão, Sebastião, que é fabricante e tocador de tambores e reco-reco, junto com Antônio, lideram a luta pela regularização do território quilombola. No ano de 2012, as funções de cabeceiras do jongo estavam sendo exercidas por Aridéia dos Santos e por sua irmã Luzinete dos Santos Nascimento (esposa de Sebastião), que também eram lideranças na igreja católica. Os tocadores de tambores são também Domingos Nascimento Tomaz, Valdecir Lucindo e Adilson Sobrinho dos Santos e os tocadores de recoreco são também Santos Nascimento e Padeci Tomaz. Quanto à idade desses integrantes, em 2012, variavam entre 47 e 70 anos.

O jongo de Santo Antônio faz parte de um projeto político de suas lideranças na construção do território quilombola, que visa inserir os jovens na brincadeira para mantê-los na comunidade e evitar que migrem para os centros urbanos. Assim como Antônio Lucindo recorreu ao auxílio do santo para combater uma enfermidade, e o jongo surge como retribuição ao mesmo santo; mestre Antônio Nascimento acredita que o Jongo de Santo Antônio ressurgiu com ele como uma espécie de remédio para combater o que ele considera uma enfermidade social - os entorpecentes - que vinham rondando a vida dos jovens da comunidade que migravam para a cidade de São Mateus. Neste caso, Antônio Nascimento entende que o trabalho de um mestre tradicional consiste em orientar os jovens para a valorização dos saberes de seus antepassados que "se divertiam por liberdade e prazer". Entende também que as famílias têm o dever e um papel social importante na transmissão de saberes tradicionais coletivos que assegurem a permanência de jovens e crianças no território, porque eles são os quilombolas do presente e do futuro. 


\section{3. "Caxambu da Santa Cruz": um demarcador da identidade quilombola em Monte Alegre}

O "Caxambu da Santa Cruz", da comunidade quilombola de Monte Alegre (localizada no meio rural do município de Cachoeiro de Itapemirim), é uma denominação local para um grupo específico de brincantes de caxambu e que está associada aos jongos, que são os pontos cantados nas chamadas rodas de caxambu. Ele é uma herança cultural deixada pelo antigo quilombola Adão (bisavô da atual mestra do grupo, Maria Laurinda Adão) e por outros ancestrais da comunidade, tornando-se, assim, uma referência cultural apropriada por parte de seus integrantes para delimitar sua identidade quilombola. Essa comunidade foi reconhecida como remanescente de quilombo pela Fundação Cultural Palmares do Ministério da Cultura em 2005, e seu território se encontra em processo de regularização no Instituto Nacional de Colonização e Reforma Agrária (INCRA) há mais de 10 anos, mas não há nenhuma previsão de titulação definitiva do mesmo.

Além de ser herança do antigo Adão, o caxambu está relacionado também a outros ancestrais que são personagens da memória da comunidade, como José Ventura (avô materno de Maria Laurinda e Adevalmira), "velho" Sabino, Etelvina, Rufina, Emília e Verício, todos caxambuzeiros e jongueiros velhos do passado, que viveram nos séculos XIX e XX. Segundo o senhor Erotildes de Oliveira (que era conhecido como Tio Totô), neto de Etelvina e de Emília, que entrevistei em 2005, quando ele tinha 95 anos, o Caxambu da Santa Cruz tinha cerca de 200 anos. O exemplo mais enigmático acerca da associação entre caxambu e saberes espirituais é o Adão, que foi escravizado na antiga Fazenda Boa Esperança, mas, segundo os seus descendentes, era um "negro fujão". Inconformado com a situação de escravizado, Adão fugia, mas

era capturado por capitães-do-mato. Por isso, ao cair da noite, era acorrentado no tronco, mas, em função de seus saberes espirituais, ele conseguia desatar as correntes e passava uma parte da noite em liberdade, pois fugia para a Serra da Boa Conserva, nas proximidades do Sertão da Pedra Lisa, onde encontrava outros quilombolas que dançavam caxambu. Para manter em segredo suas ações e o paradeiro do quilombo, relatam que Adão voltava para a fazenda no decorrer da madrugada e reatava as correntes ao tronco. Dizem que, além de Adão, outros quilombolas (homens e mulheres) se deslocavam durante as noites para o mesmo lugar, onde além de dançar caxambu, também 
namoravam e estabeleciam trocas de saberes espirituais. A outra personagem da memória sobre o caxambu é Emília, que era da localidade de Tapera, atual comunidade de Vargem Alegre e local do Caxambu Alegria de Viver, no mesmo município. Ao se casar com Verício, que era escravizado na Fazenda Monte Alegre, ela teria recebido um caxambu (tambor) como presente de casamento de outros caxambuzeiros da Tapera. No final de sua vida, Emília transmitiu a guarda do referido caxambu, assim como os saberes relativos a ele, para os irmãos José e Marcelino Ventura. José Ventura casou-se com Laurinda Dias (que veio a ser avó materna de Maria Laurinda, de quem ela herda o nome) e Marcelino casou-se com Matilde Adão, filha do velho Adão. Os referidos irmãos deram continuidade ao processo de transmissão cultural do caxambu e, posteriormente, José o transferiu para seus filhos Nelson e Eremita Ventura Adão. Após a morte de Nelson, Eremita se converteu à Igreja Assembleia de Deus, e entregou o tambor para sua filha Maria Laurinda Adão pedindo que ela tomasse conta do caxambu, pois havia vindo de seu avô. Assim, Maria se torna herdeira dos nomes, do caxambu e de uma espiritualidade que seus antepassados de origem banto a transmitiram.

$\mathrm{Na}$ liderança do Caxambu da Santa Cruz, ao lado de Maria Laurinda Adão estão Adevalmira Adão (conhecida como Ilinha) e seu filho Adão Ventura, respectivamente irmã e sobrinho da mestra, que são os tocadores dos dois tambores do grupo. Duas dessas pessoas são também dirigentes do Centro Espírita São Jorge (Umbanda): Maria Laurinda é mãe-de-santo e Adevalmira é cambona, isto é, auxiliar da mãe-de-santo.

A principal festa do Caxambu da Santa Cruz ocorre no dia 13 de maio, data da assinatura da Lei Áurea. Ao contrário de uma comemoração da Abolição da Escravatura, trata-se de uma festa em memória aos caxambuzeiros do passado e Pretos Velhos que se encontram vivos também nos rituais religiosos. A festa mantém viva as lembranças e os saberes desses heróis esquecidos e invisibilizados pelas histórias oficiais, sendo também uma celebração onde ocorre a transmissão desses saberes. Neste dia é preparada uma feijoada que é consumida pelos participantes da festa, na qual se colocam, entre outras coisas, bananas, fruta que está relacionada à memória do caxambu. Sobre as bananeiras e seus frutos existem diversas narrativas que as relacionam aos saberes de seus antepassados. Relatam que no tempo do cativeiro, alguns de seus ancestrais, realizavam uma roda de caxambu à noite, 
plantavam uma bananeira e naquela mesma noite, à meia-noite, cantavam um caxambu de "encante" ou de "mandinga", a bananeira produzia e amadurecia seus frutos, de modo que os participantes da festa se alimentavam dessas frutas. Em função desses saberes, alguns dos mais velhos dizem que a espécie da bananeira que sofria essa intervenção sobrenatural do "encante" produz um tipo de banana que é conhecida como Pai João, cultivada ainda hoje em Monte Alegre.

Faz parte da tradição e dos preparativos da grande roda de caxambu na festa de 13 de maio, providência de madeira para acenderem uma fogueira para iluminar a noite, aquecer e afinar o couro do tambor, a ser tocado pelos dois integrantes já mencionados. Faz parte das narrativas das festas e do surgimento dos instrumentos, além daquela do tambor "buliado" doado para Emília como presente de casamento, uma segunda narrativa que afirma que os instrumentos de percussão usados na primeira festa após saberem da assinatura da Lei Áurea eram caixas de madeira doadas pelo senhor de escravos. No entanto, os caxambuzeiros abandonaram as caixas doadas pelo senhor, ficando apenas com os instrumentos no formato circular "buliado", um dos quais denominado Caxambu da Santa Cruz, que pode estar relaciona aos encantes herdados de seus ancestrais.

Segundo Maria Laurinda, para ser um caxambuzeiro independe de religião e que a associação com as práticas religiosas dos africanos adveio do fato de no passado existirem pessoas que acreditavam que no caxambu fazia-se mandinga. Isso se devia aos jongueiros que sabiam cantar jongos de amarração, no sentido de que o amarrado rodava sem sair do lugar e posteriormente caía e permanecia deitado no meio da roda até amanhecer o dia, quando o efeito do encantamento acabava. As mandingas advinham das habilidades argumentativas de alguns caxambuzeiros em amarrar outros por meio de desafios musicais. Aquele que era desafiado por meio de um ponto de jongo e não conseguisse responder ao primeiro ponto ia ficando cada vez mais amarrado porque o desafiador lhe amarrava ainda mais com novos pontos desafiantes. A crença de que havia mandinga no jongo advinha do poder de encantamento daquele que era mais hábil com as palavras sobre outro que tinha menos poder argumentativo. Assim, o conteúdo das palavras tinha o poder de imobilizar aquele que não conseguia revidar com novos desafios argumentativos, ficando, segundo os 
jongueiros, amarrado pelo jongueiro que lançava o primeiro ponto ou jongo de amarração.

A noção de uma circularidade aberta construída pelos ancestrais livres e os que tinham anseio por liberdade pode ser interpretada a partir da expressão "roda", pois ela desencadeia movimentos para o passado e para um futuro autônomo, surgindo assim a preocupação da mestra e de outras lideranças locais em transmitirem os saberes do caxambu para as crianças, inserindo-as na roda e ensinando-as a serem "tiradoras de jongos", enquanto versos desafiadores e comunicadores da liberdade de cantar e pronunciar sonhos de autonomia produtiva em um território próprio.

\section{4. "Mãe África, pátria amada Brasil": o jongo na comunidade quilombola de Cacimbinha e Boa Esperança}

Cacimbinha e Boa Esperança, localizadas no município de Presidente Kênnedy, sul do Espírito Santo, são reconhecidas pela Fundação Cultural Palmares do Ministério da Cultura como uma única comunidade quilombola desde 2004, onde existem cerca de 150 famílias. No entanto, quanto ao processo de reconhecimento do território quilombola por parte do Instituto Nacional de Colonização e Reforma Agrária (INCRA), segundo um líder local, não foi adiante, pois não houve interesse da maior parte da comunidade.

O presente texto é escrito a partir de entrevistas realizadas no ano de 2012 com "jongueiros velhos" das comunidades acima, especificamente a senhora Edna dos Santos (nascida em 1935) e o senhor Jorge dos Santos (nascido em 1942). Eles nomeiam outras "jongueiras velhas" locais, como Dona Nadir, Dona Libera e Dona Fia. "Mãe África, pátria amada Brasil" é o nome que os jongueiros locais atribuíram ao seu grupo e que está escrito em sua bandeira que, por sua vez, é exibida nos momentos de apresentação do jongo dentro e fora da comunidade.

Esses líderes, no que tange à memória da comunidade e do jongo, reconstroem o passado a partir de seus pais, avós e tios. Para Dona Edna, a comunidade teria se iniciado em Jibóia, localidade vizinha de Boa Esperança, onde nasceram e viveram Manoel João Filho e Joaquina 
Maria das Neves, pais de Dona Edna. No entanto, dizem que Manoel tinha cinco esposas, uma delas na comunidade quilombola de Graúna, no município de Itapemirim e as demais em Boa Esperança. Por isso, defendem que muitos moradores de Cacimbinha, Boa Esperança e Graúna são parentes entre si.

Dona Edna, em sua infância, aprendeu a dançar e cantar o jongo com jongueiros da região de Campos dos Goitacazes (RJ), que se apresentavam na festa de Nossa Senhora das Neves, na igreja localizada no litoral do município de Presidente Kênnedy. Nessa festa, também os "jongueiros velhos" da comunidade (já falecidos) dançavam e cantavam o jongo, com os quais o processo de aprendizagem de Dona Edna teve continuidade. Na festa das Neves, o jongo começava na noite de 04 de agosto, véspera do dia da santa, e só parava no dia seguinte por volta das 10 horas da manhã. $\mathrm{O}$ mesmo ocorria com o jongo na comunidade, onde "a brincadeira amanhecia o dia" ao redor da fogueira. Atualmente uma roda de jongo vai até no máximo duas horas da manhã e a fogueira permanece para aquecer e afinar o couro dos tambores.

Jorge dos Santos, nascido em Itapemirim, foi para Cacimbinha com cerca de 10 anos, onde sua mãe havia nascido e vivia sua avó materna, e com cerca de trinta anos casou-se com Lourdes, que nasceu em Boa Esperança, onde vive com sua família ainda hoje em uma terra deixada como herança pelo pai de Lourdes. Seu Jorginho, como é conhecido, aprendeu a dançar e cantar jongo em Cacimbinha, na casa de sua avó, pois seus tios maternos - Mano Quincas e Eugênio - tinham jongo e com frequência realizavam festas. Afirma que os velhos iam trabalhar e as crianças passavam a brincar de bater tambor, dançar e cantar jongo que aprendiam ouvindo e vendo os adultos. Assim, afirma que aprendeu "com aquele povo velho do jongo de Cacimbinha".

Entre os santos de devoção dos jongueiros velhos locais, além de Nossa Senhora das Neves, estão São Jorge, São Benedito e Santo Antônio. As devoções à primeira santa estão relacionadas ao período da escravidão, quando a igreja para a mesma foi construída pelos escravizados sob a ordem religiosa dos Jesuítas, como parte da antiga Fazenda Muribeca, onde as festas continuaram acontecendo e os grupos jongueiros do sul do ES e do norte Fluminense apareciam para apresentarem seus talentos artísticos e musicais e interagirem entre si. São Jorge, que é comemorado dia 23 de abril, é o padroeiro da igreja católica de 
Cacimbinha, enquanto o padroeiro da igreja de Boa Esperança é São Benedito, cuja festa é celebrada no mês de outubro.

Quanto aos instrumentos do grupo, trata-se de dois antigos tambores fabricados de madeira maciça denominada pitomba, na época em que Edna e Jorge dos Santos eram crianças, já existiam e, atualmente, ficam guardados na escola de Cacimbinha. Apenas o couro de boi é trocado quando fura, mas a madeira continua a mesma. A localidade vizinha da Jibóia é um dos lugares de memória entre os "jongueiros velhos". Afirmam que os tambores da Jibóia rufavam tão alto que podiam ouvir de longe, pois eram "tambores machos" e os de Cacimbinha e Boa Esperança, ao ouvirem o som, iam se juntar a turma de jongueiros da Jibóia, onde brincavam a noite toda. Por isso, os tambores grandes passaram a ser denominados "espalhadores" porque "botam a boca no mundo" e espalhavam o som à longa distância, comunicando que os jongueiros e quilombolas estavam fazendo festa. Deste modo, as narrativas de Jorginho demonstram que ele recebeu influência do jongo que se fazia na Jibóia, do qual herdou a forma de tocar e de denominar o tambor. O toque desses tambores é estimulador de lembranças dos pontos de jongo cantados pelos antigos jongueiros. É como se os toques transportassem no tempo a alma e os saberes dos antepassados e fossem incorporados aos seus herdeiros na roda de jongo. A esse respeito, o senhor Jorginho afirma: “O tambor a gente já tem de lá pra cá...”, isto é, dos antepassados para os seus descendentes.

As "roupas de brincar" constituem outra simbologia de distinção desse grupo de jongos, onde a saia das mulheres é estampada e a blusa é branca, enquanto para os homens a camiseta também é branca e a calça é de cor indefinida. No caso de dona Edna e seu Jorginho, acrescenta-se um chapéu. As roupas são adquiridas e fabricadas por eles mesmos ou por costureiros(as) contratados e não existem montagem e uniformização das vestes ritualísticas.

No que diz respeito ao processo de transmissão cultural do jongo entre gerações, os "jongueiros velhos" relatam que aprenderam a dançar e cantar ainda criança. Enquanto os velhos estavam no jongo, as crianças imitavam as cantigas em separado, no que ainda hoje é denominado "brincadeira de roda". Atualmente existe ali um grupo de jongo mirim, onde os protagonistas são as crianças, apesar de o mestre ser também o senhor Jorge dos Santos. Nas apresentações do jongo, um grupo 
formado por crianças sempre se apresenta primeiro, usando os mesmos tambores dos adultos. Quando o grupo dos adultos dança, as crianças permanecem ao redor dançando e cantando. Nas escolas, uma em Cacimbinha e outra em Boa Esperança, bem como no Centro de Educação Infantil (onde trabalha como educadora, Efigênia, filha do seu Jorginho), os "jongueiros velhos" (seu Jorginho, dona Edna e dona Nadir) têm sido convidados esporadicamente a ensinarem jongo para as crianças. No entanto, os jongueiros defendem que o maior processo de transmissão dessa prática cultural ocorre, em primeiro lugar, na roda de jongo; em segundo, nas famílias, principalmente quando os pais e mães são ou foram jongueiros e ensinam as crianças desde cedo a cantarem e dançarem o jongo.

\section{Considerações conclusivas}

Para finalizar este artigo cabe enfatizar que o seu foco central de partida não foram os bens culturais como os jongos e caxambus, mas sim as comunidades protagonistas na produção desses bens, isto é, as comunidades dos quilombos. Neste sentido, não foi a pesquisa etnográfica que elegeu esses bens culturais como elementos demarcadores das identidades e diferenças, mas sim as próprias comunidades onde a pesquisa foi desenvolvida, cujo foco incidiu sobre os processos de organização da vida comunitária, que apresentaram esses bens como específicos de comunidades negras e quilombolas. Assim, as comunidades quilombolas aqui descritas tomam o jongo e o caxambu como referência cultural para demarcarem suas identidades.

Na perspectiva das organizações de movimentos negros e quilombolas, nas quais se inclui também as mobilizações dos jongueiros do Sudeste, o jongo é um bem cultural de coletividades negras e/ou quilombolas dos meios rurais e urbanos. Apesar do reconhecimento do jongo como patrimônio cultural do Brasil, as coletividades dos jongueiros, conforme verifiquei na pesquisa, entendem que as ações de salvaguarda de jongos e caxambus nunca foi uma política de Estado, mas sim um protagonismo dos próprios agrupamentos jongueiros com a organização de suas reuniões e eventos celebrativos, que consiste em rememorar, comemorar, recriar e transmitir coletivamente esses bens às novas gerações. Afirmam que muito antes da política de reconhecimento 
estatal do jongo como patrimônio cultural brasileiro, as comunidades negras e quilombolas existentes nos meios rural e urbano já reconheciam suas celebrações de jongos e caxambus como referências culturais suas, visto que essas são heranças culturais provenientes de seus antepassados. Assim, na visão dos quilombolas e jongueiros, a salvaguarda do jongo não está apenas no registro desse bem cultural, mas principalmente na práxis sociocultural, que assegura às condições sociais dignas aos integrantes das comunidades e a transmissão de seus saberes às novas gerações por meio da realização de suas festas enquanto eventos que celebram e comemoram as conquistas e as diversas dimensões da vida comunitária.

Concluo também que as chamadas rodas de jongos e caxambus realizam movimentos circulares, na maioria dos casos em sentido anti-horário e, em outros momentos, em sentido horário, sinalizando, segundo as explicações de alguns mestres desses saberes tradicionais afros, para um movimento de retorno e ao encontro de saberes herdados dos ancestrais e, ao mesmo tempo, ao circular em sentido horário, sinaliza para a importância do não fechamento da roda e o isolamento das comunidades e dos grupos geracionais em si mesmos, e sim para a transmissão desses saberes para as novas gerações. Assim, as rodas de jongos, enquanto práxis socioculturais, desencadeiam pelo menos dois movimentos: um que é aquele do anti-esquecimento das origens e dos saberes herdados dos ancestrais dessas comunidades; o outro é aquele da construção de um futuro de autonomia para as crianças e os jovens das comunidades quilombolas, ensinando-as a serem desafiadoras de práticas e ideologias que empreendem um movimento contrário à busca da autonomia das comunidades dos quilombos.

\section{Referências}

ASSOCIAÇÃO BRASILEIRA DE ANTROPOLOGIA (ABA). Documento do Grupo de Trabalho sobre Comunidades Negras Rurais. Boletim Informativo Nuer, v. 1, n. 1, 1997 [1994].

ADÃO, Maria Laurinda. Caxambu. 2013. Banco de dados Programa de Pesquisa e Extensão Jongos e Caxambus: culturas afro-brasileiras no Espírito Santo. Entrevista concedida a Osvaldo M. Oliveira. Cachoeiro de Itapemirim (ES), 2013. 
ALMEIDA, A. W. B. Os quilombos e as novas etnias. Revista Palmares, n. 5, 2000.

. Os quilombos e as novas etnias. In: O’DWYER, Eliane C. (org.). Quilombos: identidade étnica e territorialidade. Rio de Janeiro: FGV/ABA, 2002.

Associação Brasileira de Antropologia (ABA). Documento do Grupo de Trabalho sobre Comunidades Negras Rurais. In: Boletim Informativo NUER, Vol. 1, n. 1, 1997 [1994].

BARTH, Fredrik. Introdução. In: Los grupos étnicos y sus fronteras. La organizaçión social de las diferencias culturales. México: Fondo de cultura económica, 1976 [1969].

Problems in conceptualizing cultural pluralism, with illustrations from Somar, Oman. In: Maybury-Lews, David. The Prospects for Plural Societies. The American Ethnological Society. Washington, 1984.

Temáticas permanentes e emergentes na análise da etnicidade. In: VERMEULEN, Hans \& GOVERS, Cora (Orgs). Antropologia da etnicidade: para além de ethnic groups and boundaries. Lisboa: Fim de Século, 2003 [1994].

O guru, o iniciador e outras variações antropológicas. Rio de Janeiro: Contra Capa, 2000.

BRASIL. Constituição Federal de 1988. Promulgada em 5 de outubro de $1988 . \quad$ Disponível em <http://www.planalto.gov.br/ccivil_03/constituicao/constituição.htm>. BRASIL. Decreto Presidencial $\mathbf{s} / \mathbf{n}^{\mathbf{0}}$, de 15/12/2010, publicado no Diário Oficial da União em 16/12/2016. Processo $\mathrm{N}^{\circ}$ 54340.000582/2005-15

FERREIRA, Simone Raquel Batista. "Donos do lugar": a territorialidade quilombola do Sapê do Norte - ES. Tese (Doutorado em Geografia). Programa de Pós-Graduação em Geografia da Universidade Federal Fluminense. Niterói (RJ), 2009.

IPHAN/MinC. Dossiê Jongo do Sudeste. Brasília: Iphan, 2005.

LEITE, Ilka Boaventura. Território Negro em área Rural e Urbana: algumas questões. Textos e Debates No. 2. Florianópolis: NUER/UFSC, 1991. 
MACIEL, Cleber. Negros no Espírito Santo. DEC, SPDC/ UFES: Vitória - ES, 1994.

MARINATO, Francieli Aparecida. Escravidão, quilombos, quilombolas e fazendeiros na origem da comunidade de Monte Alegre. In: OLIVEIRA, Osvaldo Martins de (coord.). Relatório técnico de identificação da comunidade remanescente de quilombos de Monte Alegre. Projeto territórios quilombolas no Espírito Santo. Vitória: UFES/INCRA, 2006.

MARTINS, Robson L. M. Em louvor a "Sant'Anna": notas sobre um plano de revolta escrava em São Matheus, norte do Espírito Santo, Brasil, em 1884. Estudos Afro-Asiáticos, Rio de Janeiro, n. 38, 2000.

MOREIRA, Vânia. A guerra contra os índios botocudos e a formação de quilombos no Espírito Santo. Afro-Ásia, Salvador, n. 41, 2010.

MUNANGA, Kabengele. Origem histórica do quilombo na África. Revista USP, São Paulo, n. 28, p. 56-63, dez.-fev. 1995/1996.

NASCIMENTO, Abdias. Quilombismo: documentos da militância pan-africanista. Petrópolis: Vozes, 1980.

NASCIMENTO, Antônio. Jongo. 2012. Banco de dados Programa de Pesquisa e Extensão Territórios e territorialidades rurais e urbanas: processos organizativos, memórias e patrimônio cultural afro-brasileiro nas comunidades jongueiras do Espírito Santo. Entrevista concedida a Osvaldo M. Oliveira e Luiz H. Rodrigues, São Mateus (ES), 30 jun. 2012.

NASCIMENTO, Sebastião. Jongo. 2012. Banco de dados Programa de Pesquisa e Extensão Territórios e territorialidades rurais e urbanas: processos organizativos, memórias e patrimônio cultural afro-brasileiro nas comunidades jongueiras do Espírito Santo. Entrevista concedida a Osvaldo M. Oliveira e Luiz H. Rodrigues, São Mateus (ES), 30 jun. 2012.

NERY, João Batista Correa. A cabula: um culto afro-brasileiro. Vitória: Comissão Espírito-Santense de Folclore, 1963.

OLIVEIRA, Osvaldo M. Quilombo do Laudêncio, município de São Mateus (ES). In: O’DWYER, Eliane Cantarino (Org.). Quilombos: identidade étnica e territorialidade. Rio de Janeiro: FGV/ABA, 2002. 
. O projeto político do território negro de Retiro e suas lutas pela titulação das terras. 2005. Tese de Doutorado em Antropologia. PPGAS-UFSC. Florianópolis, 2005.

Comunidades quilombolas no estado do Espírito Santo: Conflitos sociais, consciência étnica e patrimônio cultural. RURIS, v. 5, p. 141-171, 2011 a.

A guerra das raízes: memória social e conflitos territoriais em comunidades quilombolas no Espírito Santo. In: IX Reunião de Antropologia do Mercosul, 2011b, Curitiba - PR. http://www.sistemasmart.com.br/ram/arquivos/ram.

POLLAK, Michel. Memória, esquecimento, silêncio. Estudos Históricos, RJ, vol. 2, n. 3, 1989.

Memória e identidade social. In: Estudos Históricos, RJ, vol. 5, n. 10, 1992.

SANTOS, Edna. Jongo. 2012. Banco de dados Programa de Pesquisa e Extensão Territórios e territorialidades rurais e urbanas: processos organizativos, memórias e patrimônio cultural afro-brasileiro nas comunidades jongueiras do Espírito Santo. Entrevista concedida a Osvaldo M. Oliveira, Aissa Guimarães, Clair da C. Moura Júnior e Larissa Albuquerque da Silva. Presidente Kennedy (ES), 2012.

SANTOS, Jorge. Jongo. 2012. Banco de dados Programa de Pesquisa e Extensão Territórios e territorialidades rurais e urbanas: processos organizativos, memórias e patrimônio cultural afro-brasileiro nas comunidades jongueiras do Espírito Santo. Entrevista concedida a Osvaldo M. Oliveira, Aissa Guimarães, Clair da C. Moura Júnior e Larissa Albuquerque da Silva. Presidente Kennedy (ES), 2012.

WEBER, Max. Economia e sociedade. 3. ed., Brasília: Editora da UnB, 1972 [1920].

WIED-NEUWIED, Von Maximiliano. Viagem ao Brasil. Belo Horizonte/São Paulo: Itatiaia/Edusp, 1989.

Recebido em 25/05/2016

Aprovado em 30/06/2016 